\title{
Photo Catalytic Degradation of Effluent of Iron and Power Plant Industries in Aqueous Solution by CDS Nano Catalyst Using UV Irradiation
}

\author{
${ }^{1}$ Mr Manish Tillashi, ${ }^{2}$ Dr. O.N. Choubey \\ Department of Chemistry, Govt. Narmada P. G. College, Hoshangabad 461001, M.P., India,
}

\begin{abstract}
The iron and power plant industries consume significant amount of water during the power generation and finishing operations. In this operation a used water having high chemical oxygen demand contents and the waste water discharged in rivers or public sewage treatment plant. Their treatment has been a necessary aspect for human prosperity and ecological environment. This paper shows the detailed study of photo catalytic degradation of effluent carried out in the presence of an aqueous solution of CDS nano catalyst irradiated with UV light in a batch reactor. It was observe that photo catalytic degradation of effluent obey pseudo first order kinetics according to langum-uir Hinshelwood model. The influences of various factors in rate of reaction are, initial effluent concentration, catalyst concentration and UV light irradiation time on degradation efficiency were scientifically studied. The degradation of effluent was determined by Photo colorimeter and determines the COD degradation through transmittance of effluent.
\end{abstract}

Keywords: Photo catalytic degradation, CDS nano catalyst, COD, AOP's, Iron and power plant waste water.

\section{Introduction}

A wide variety of organic pollutants are introduced into the water system from various sources such as industrial effluents, agricultural runoff and chemical spills (Muszkat et al., 1994; Cohen et al., 1986). Their toxicity, stability to natural decomposition and persistence in the environment has been the cause of much concern to the societies and regulation authorities around the world (Dowd et al., 1998).

Environmental pollution is produced either by a natural source or by some anthropogenic activity, or by human. Which has an adverse effect on humans, animals, plants and materials? The inordinate population growth, fast industrialization, rapid urbanization and modified agricultural operations have intensified the pollution of air and water both and as a consequence, the human health is seriously affected by this environmental and ecological disorder. If this situation is not controlled timely, it would become a malignant problem for the survival of mankind on this planet. Environment pollution by organic pollutant also sets several ecological problems, which is increased by the fact that most of them are difficult to degrade using standard biological methods. For the removal of such recalcitrant pollutants some traditional, physical techniques such as adsorption on activated charcoal, ultra filtration, reverse osmosis and coagulation is used efficiently. Nevertheless they are nondestructive. Recently there has been considerable interest on the utilization of advanced oxidation process (AOPs) for the destruction of organic compounds in contaminated water.

Semiconductor particles have been found to act as heterogeneous photocatalysts in a number of environmentally important reactions (Blake, 2001; Pirkanniemi, \& Sillanpää, 2002; Gaya \& Abdullah, 2008). Materials such as colloidal $\mathrm{TiO} 2$ and $\mathrm{CdS}$ have been found to be efficient in laboratory-scale pollution abatement systems (Barni et al., 1995; Bellobono et al., 1994; Legrini et al., 1993; Mills \& Hunte, 1997; Halmann, 1996), reducing both organic [e.g. halogenocarbons (Gupta \& Tanaka, 1995; Martin et al., 1994; Read et al., 1996;), benzene derivatives (Blanco et al., 1996; Mao et al., 1996) detergents (Rao \& Dube, 1996), PCB's (Huang et al., 1996), pesticides (Gianturco et al., 1997;

The key advantage of this degradation method is that it can be carried out under ambient condition and lead to complete degradation of organic compounds. Among the advanced oxidation process heterogeneous photo catalysis appears as an emerging technology leading to the total mineralization of most of the organic pollutants. If a suitable semiconductors are irradiated with visible or UV light electron excitation from Valance band to conduction band results and a vacancy or hole is left in the valance band such holes have the effect of a positive charge. Thus in turn generates the formation of "holes" on the surface of the semiconductor, which can react with oxygen, water and hydroxide ion to form hydroxyl radicals. Furthermore, super oxide radicals are formed from the reaction of excited electrons with oxygen molecules. The highly reactive oxygen species so formed react with the organic pollutants resulting in their oxidation.

The kinetics of photo catalytic degradation of many organic compounds in CDS suspensions under visible irradiation has often been matched to the simple langmuir-hinshelwood equation -1

$$
\mathrm{r}=-\mathrm{dc} / \mathrm{d} \mathrm{t}
$$

......equation-1

Where $\mathrm{K}^{\prime}$ is the apparent rate constant of photo catalytic degradation. The plot of $(\mathrm{C} 0 / \mathrm{C}) \mathrm{Vs}$ time yield a 
straight line and its slop is $\mathrm{Kr}^{\prime}$ in equation -2

$$
\mathrm{t}^{1} 1 / 2=0.693 / \mathrm{K}^{\prime}
$$

equation 2

\section{Procedure for conducting the degradation experiments}

\section{Method And Material}

Stock solutions of the pollutants containing the desired concentration were prepared in double distilled water. An immersion well photochemical reactor made of Pyrex glass equipped with a magnetic stirring bar, water circulating jacket and an opening for supply of molecular oxygen was used. A simplified diagram of the reactor system is shown in Figure.

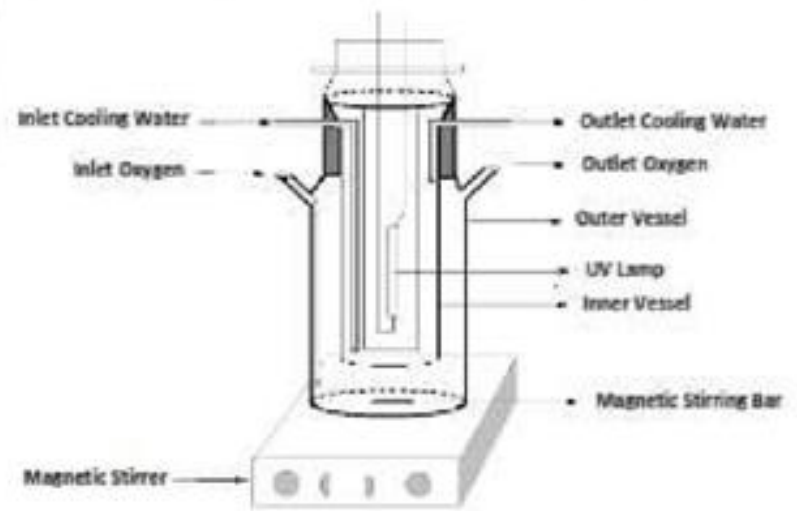

\section{CDS AS PHOTO CATALYST}

CDS is a semiconductor used as photo catalyst in various photo catalytic reactions. Generally semiconductors have large band gaps are good photo catalyst. ZnO and CDS with band gaps larger then 3ev show strong (shown in table-1) activity. The conduction and valance band potentials of both $\mathrm{ZnO}$ and CDS are larger than the corresponding redox potentials of $\mathrm{H}+/ \mathrm{H}_{2}$ and $\mathrm{H}_{2} \mathrm{O} / \mathrm{O}_{2}$ and the photo generated electron and hole can be separated efficiently. Photo catalytic mechanism of CDS nano catalyst show in below

\begin{tabular}{|l|l|}
\hline Photo Catalyst & Band gap (ev) \\
\hline $\mathrm{ZnO}$ & 3.2 \\
\hline $\mathrm{TiO}$ & \\
\hline $\mathrm{CdS}$ & 3.1 \\
\hline$\propto-\mathrm{Fe}_{2} \mathrm{O}_{3}$ & 2.3 \\
\hline
\end{tabular}

Table-1

\section{Chemistry Of Photo Catalytic Reaction}

When photo catalyst nano CDS absorb the ultraviolet light from sun light or different sources ,then it will produce a pair of electron and holes. The valance electron of CDS are become excited when they get the energy from UV light or illuminated by sources. If the energy of excited electron is greater than the threshold energy then electron goes to valance to conduction band of CDS and create the negative electron and positivehole pair. The stage is referred as semiconductor photo excitation stage. Positive holes of CDS break apart the water molecule to form hydrogen gas and hydroxyl radical and the negative electron react with oxygen molecule and form super oxide anion, This cycle continue when light is available.

CDS $+\mathrm{h} v \rightarrow \mathrm{e}_{\mathrm{cb}}^{-}$(Conduction band electron) $+\mathrm{h}_{\mathrm{vb}}{ }^{+}$(Valance band hole) equation-1

Due to the higher band gap CDS can be activated only by UV irradiation of wavelength below 385 $\mathrm{nm}$. The photo generated valance band hole and valance band electrons can either recombine to liberated heat , or make their own ways to the surface of CDS, where they can react with species absorbed on the surface of catalyst shown in Equation 3 and 6.

$$
\begin{aligned}
& \mathrm{h}_{\mathrm{vb}}++\mathrm{H}_{2} \mathrm{O} \rightarrow \mathrm{HO}^{\bullet}+\mathrm{H}^{+} \quad \ldots \ldots \ldots \ldots \ldots \ldots \text { equation-2 } \\
& \text { Organic molecule }+\mathrm{h}_{\mathrm{vb}}{ }^{+} \rightarrow \text { oxidation products, } \quad \text {.................. equation-3 } \\
& \mathrm{e}^{--} \mathrm{cb}+\mathrm{O}_{2} \quad \rightarrow \mathrm{O}_{2} \bullet-, \quad \text {................... equation-4 } \\
& \mathrm{O}_{2}{ }^{\bullet}+\mathrm{H}^{+} \rightarrow \mathrm{HO}_{2}{ }^{--} \quad \text {.................. equation-5 }
\end{aligned}
$$

Hydroxy redical $\mathrm{HO}^{\circ}$, along with per hydroxyl redical $\mathrm{HO}_{2}{ }^{\circ-}$ can oxidise the most of the organic molecule and reduce the organic load in waste water. 


\section{Experimental Set Up}

\section{Result And Discussion}

Chemicals - all chemicals are of AR grade potassium dichromate, Sulphuric acid and mercuric sulfate was used. The photo catalyst CDS nano catalyst was used.

\section{Experimental Procedure}

The photo catalytic reaction was carried out in a batch reactor with dimension of $7.5 \times 6 \mathrm{~cm}$ (height $\mathrm{X}$ diameter) provide with a water circulation arrangement in order to maintain the temperature in the range of 25 $300 \mathrm{C}$.The irradiation was carried out using $500 \mathrm{~W}$ halogen lamp. In all cases during the photolysis experiments the effluent, Potassium dichromate, sulphuric acid and mercuric sulphate solution and the catalyst was placed in the reactor and stirred magnetically with simultaneously exposure to visible light. Sample was withdrawn at periodic intervals from the reactor to assess the extent of de-colorization. The intensity of light was measured by lux meter (Lutron LX-101). A photocolorimetr was used for measuring absorbance at different time intervals at $620 \mathrm{~nm}$

\section{Effect of Concentration of effluent}

Photo catalytic degradation of effluent for different concentration of effluent like $10 \mathrm{~mL}, 15 \mathrm{~mL}, 20$ $\mathrm{mL}, 25 \mathrm{~mL}$ and $30 \mathrm{~mL}$ solution containing $30 \mathrm{mg}$ CDS nano catalyst. The change in concentration of the effluent in the solution, plotted as function of concentration of effluent. It is seen that degradation of COD value was increase with time. Table- 1 shows the $\mathrm{k}$ value of COD degradation when concentration of catalyst is constant and effluent concentration are changed.

An aliquot of $3.0 \mathrm{ml}$ was taken out from the reaction mixture at regular time intervals and the absorbance was measured at $\lambda \max =620 \mathrm{~nm}$. It was observed that the absorbance of the solution decreases with increasing time intervals, which indicates that the concentration of COD decreases with increasing time of exposure. A plot of transmittance verses time was linear and follows pseudo first order kinetics. The rate constant was measured using following expression:

$$
\mathrm{k}=2.303 \times \text { slope }
$$

The results of typical run for photo catalytic degradation of COD are shown in the Table 1 and graphically represented in Fig 1.'

Amount of $\mathrm{CDS}=30 \mathrm{mg}$

Light intensity $=17500$ lux $\quad \lambda \max =620 \mathrm{~nm}$

[Effluent Concentration $=10 \mathrm{ml}]$

\begin{tabular}{|c|c|}
\hline Sample Concentration In mL & K value/sec \\
\hline 10 & 145.7689801 \\
\hline 15 & 179.9872267 \\
\hline 20 & 197.8695555 \\
\hline 25 & 220.163829 \\
\hline 30 & 218.7425007 \\
\hline
\end{tabular}

Table 1- Effect of sample concentration

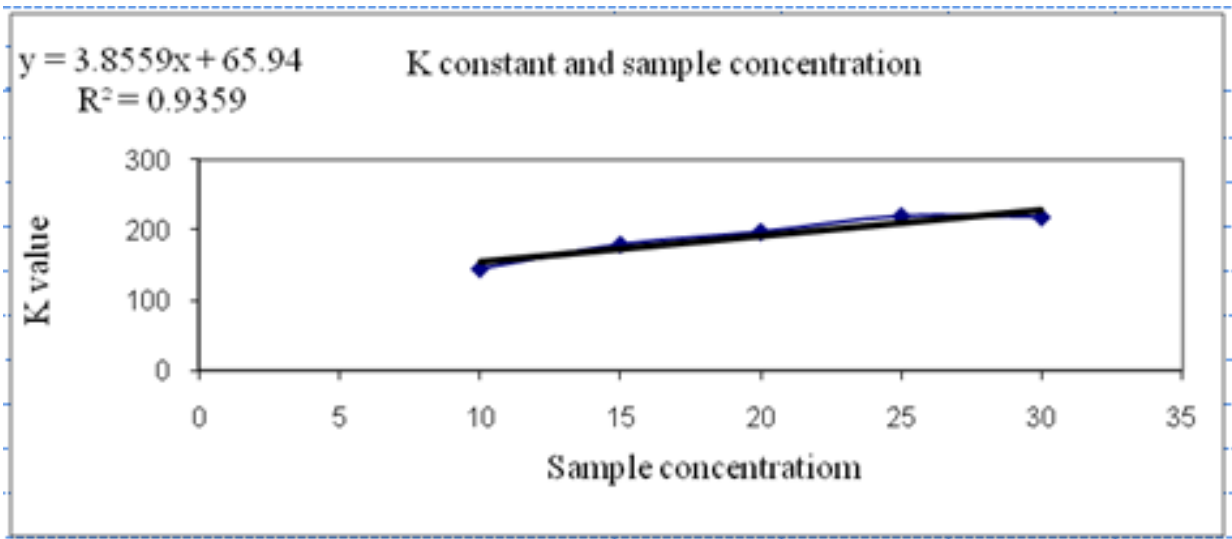

Fig-1 


\section{Effect of Concentration of catalyst}

The effect of concentration of catalyst on the rate of photo catalytic degradation was observed by taking different concentrations of catalyst and effluent concentration was constant. The results are reported in the table 2. It is obvious to expect increase in reaction rate. It is evident that as the concentration of catalyst was increased, the rate of photo catalytic degradation of COD was increased.

From the experimental result we have observed that the decrease of $\mathrm{k}$ value with increase in initial concentration of the sample and vice versa can be attributed to the decrease in the path length of photon entering the solution due to impermeability of the solution. At low concentration the reverse effect observed, hereby increasing the number of photon absorption by the catalyst. This decreasing phenomenon can further be explained in terms of the increase in requirement of catalysts surface for the increased concentration of the sample. But here the amount of catalyst had been kept constant. Hence the relative number of $\mathrm{O}_{2}{ }_{2}$ and $\mathrm{OH}^{\circ}$ radicals formed on the surface of CDS are also constant. As a result the relative number of $\mathrm{O}_{2}^{\circ}$ and $\mathrm{OH}^{\circ}$ attacking the organic molecule with increasing initial concentration of the catalyst. The plot of $\mathrm{C} 0 \mathrm{Vs} \mathrm{k}$ should yield a straight line. The $\mathrm{kr}$ and $\mathrm{k}$ values were calculated from slope of the straight line and intercept respectively. Amount of CDS $=30 \mathrm{mg} \quad, 60 \mathrm{mg}, 90 \mathrm{mg}, 120 \mathrm{mg}, 150 \mathrm{mg}$,

Light intensity $=17500$ lux $\quad \lambda \max =620 \mathrm{~nm}$

\begin{tabular}{|l|l|}
\hline Catalyst In $\mathrm{mg}$ & K Value/sec \\
\hline 30 & 94.955 \\
\hline 60 & 86.8092 \\
\hline 90 & 69.377 \\
\hline 120 & 66.787 \\
\hline 150 & 59.1111 \\
\hline
\end{tabular}

Table 2 - Effect of catalyst concentration

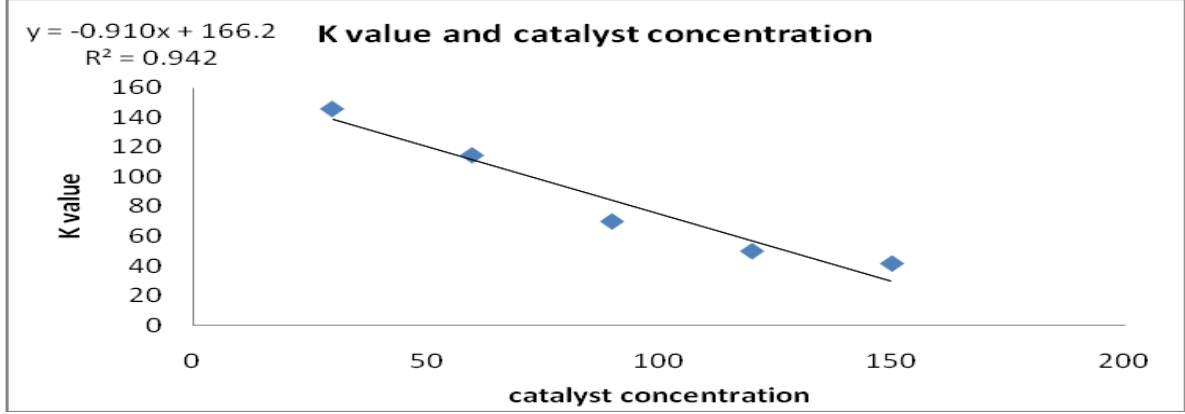

Fig-2

Effect of sample concentration on reaction rate.

In $\mathrm{X}$ axis represent the Time and $\mathrm{Y}$ axis \% transmittance.

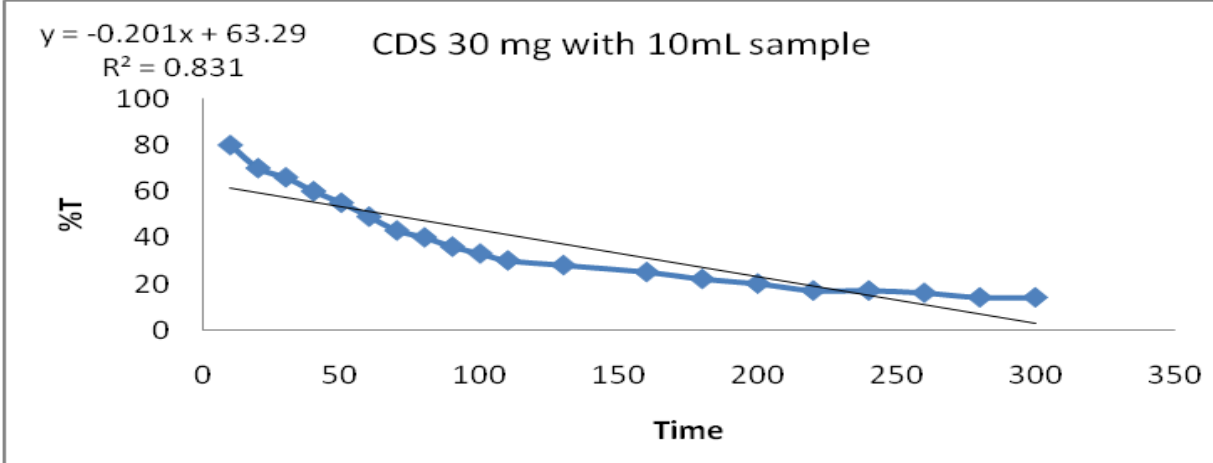

Fig-3 


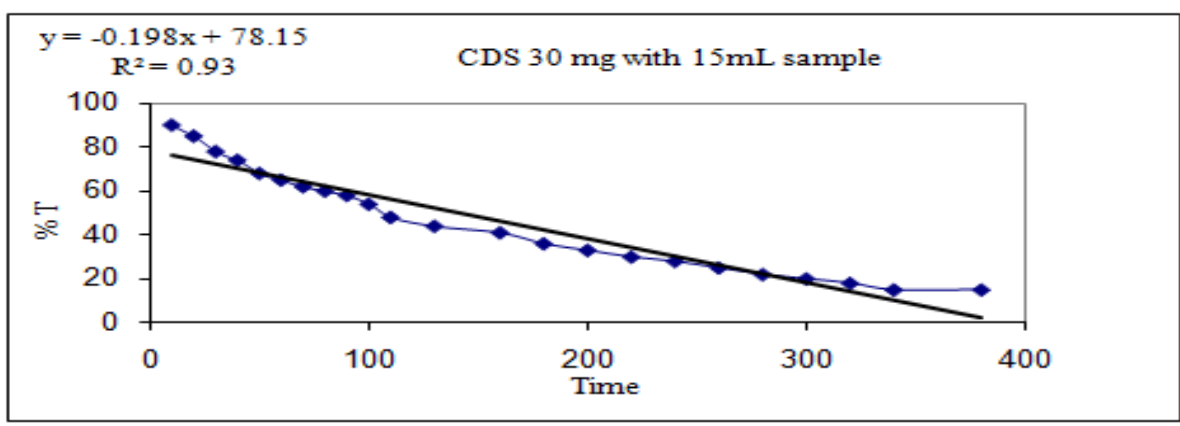

Fig-4

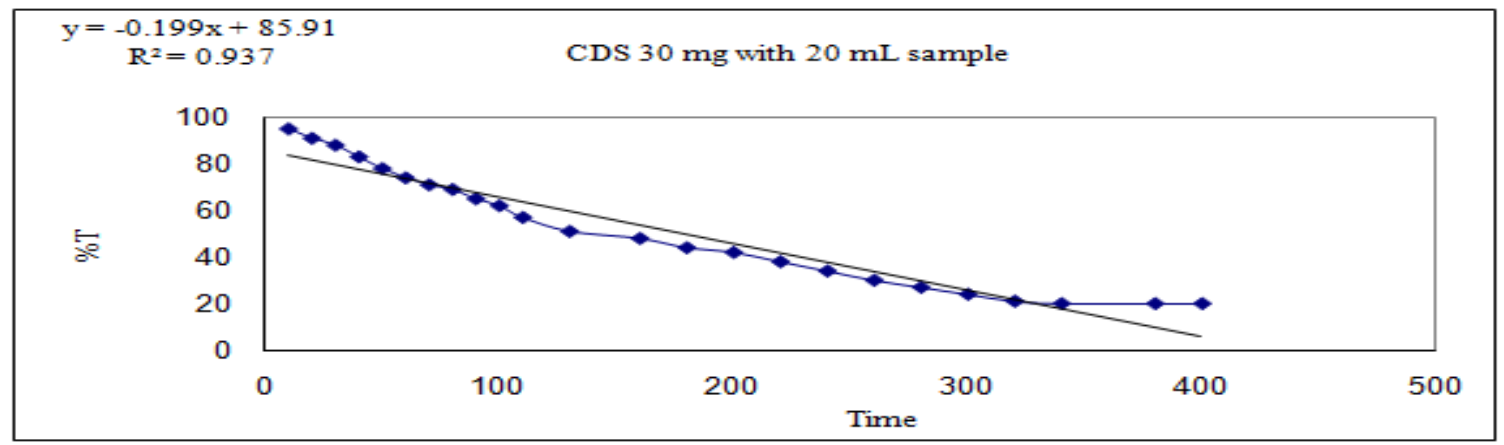

Fig-5

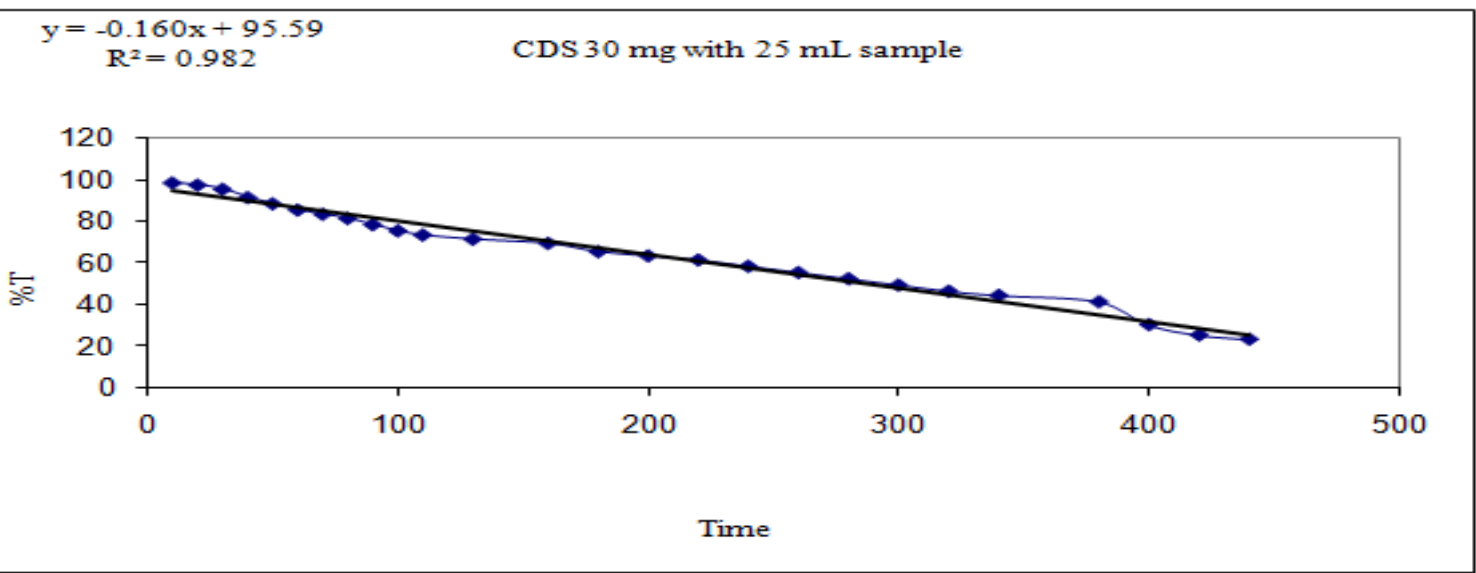

Fig-6

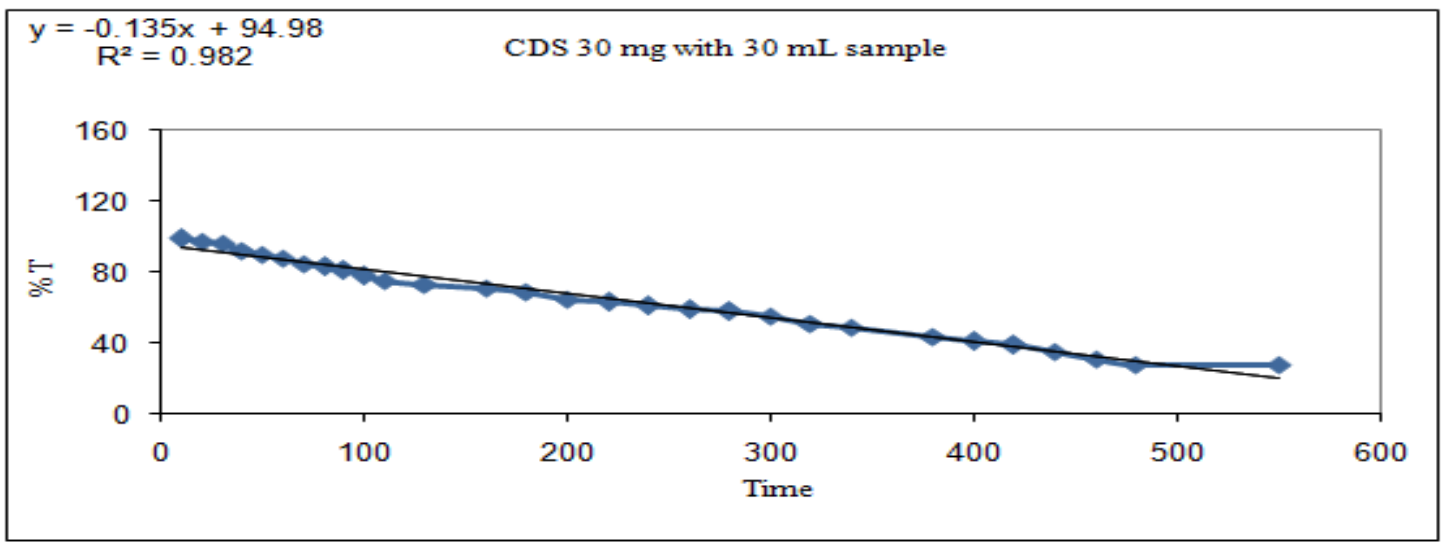

Fig-7 
Effect of Catalyst concentration on reaction rate:

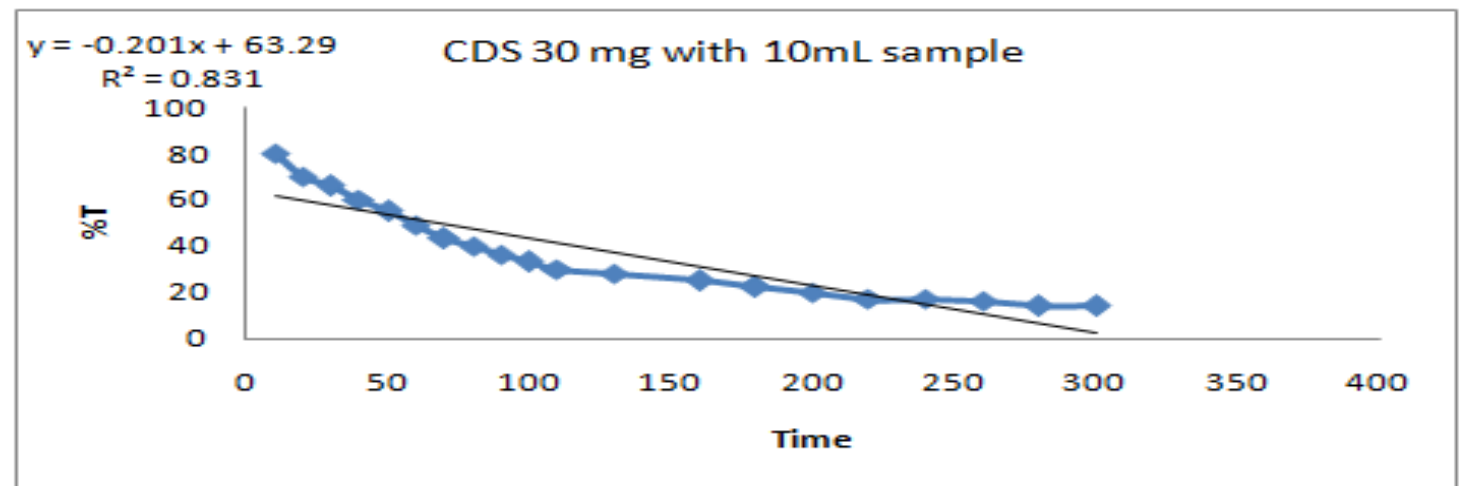

Fig-8

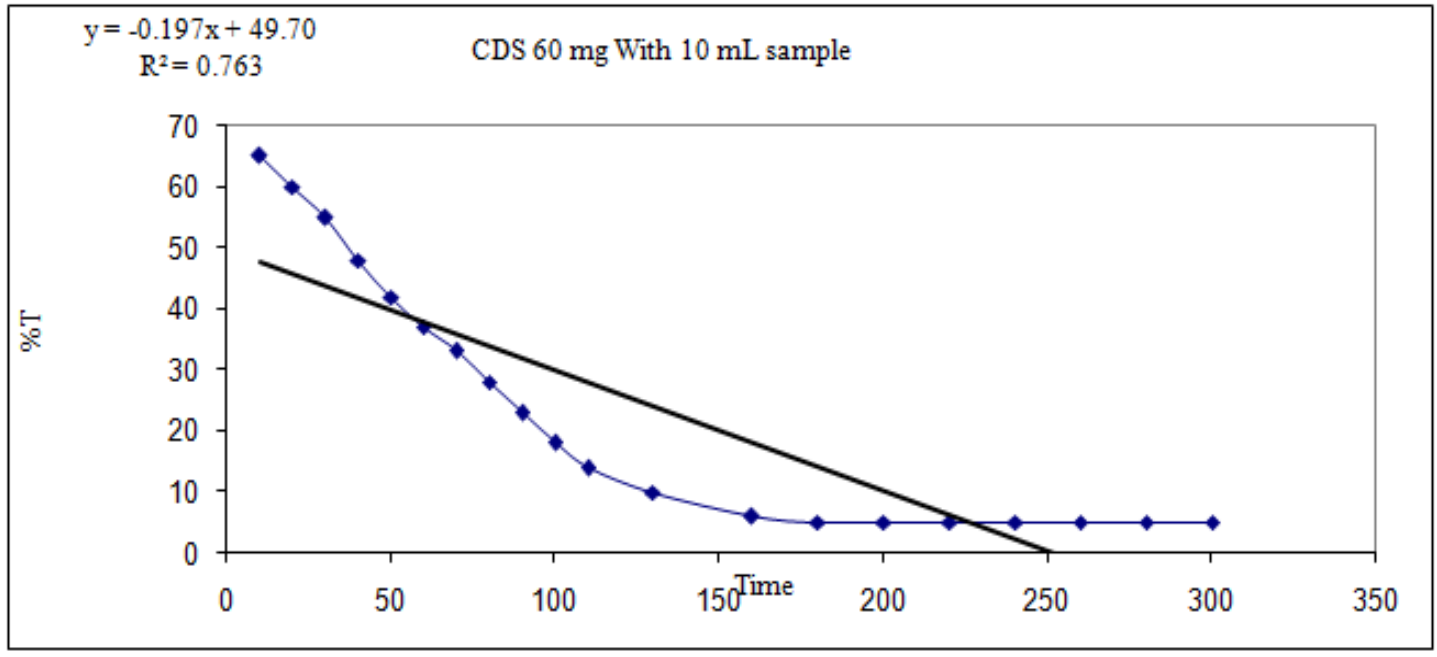

Fig-9

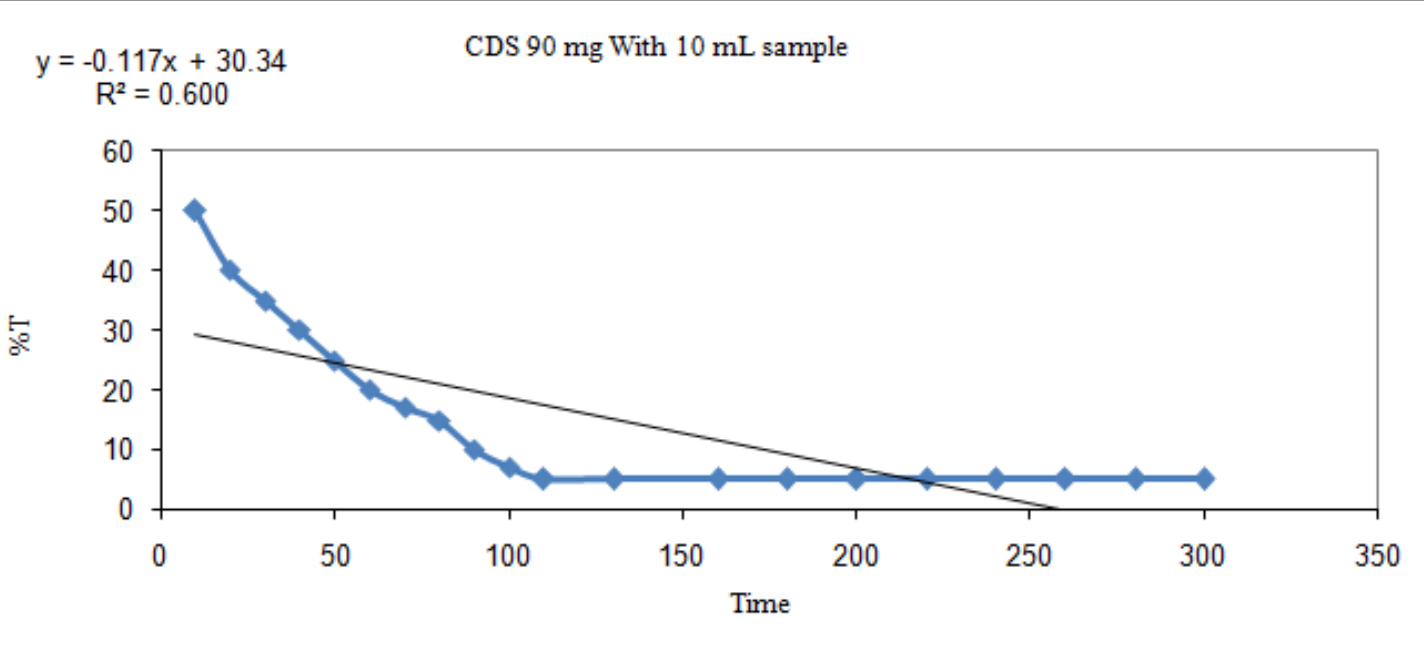

Fig-10 


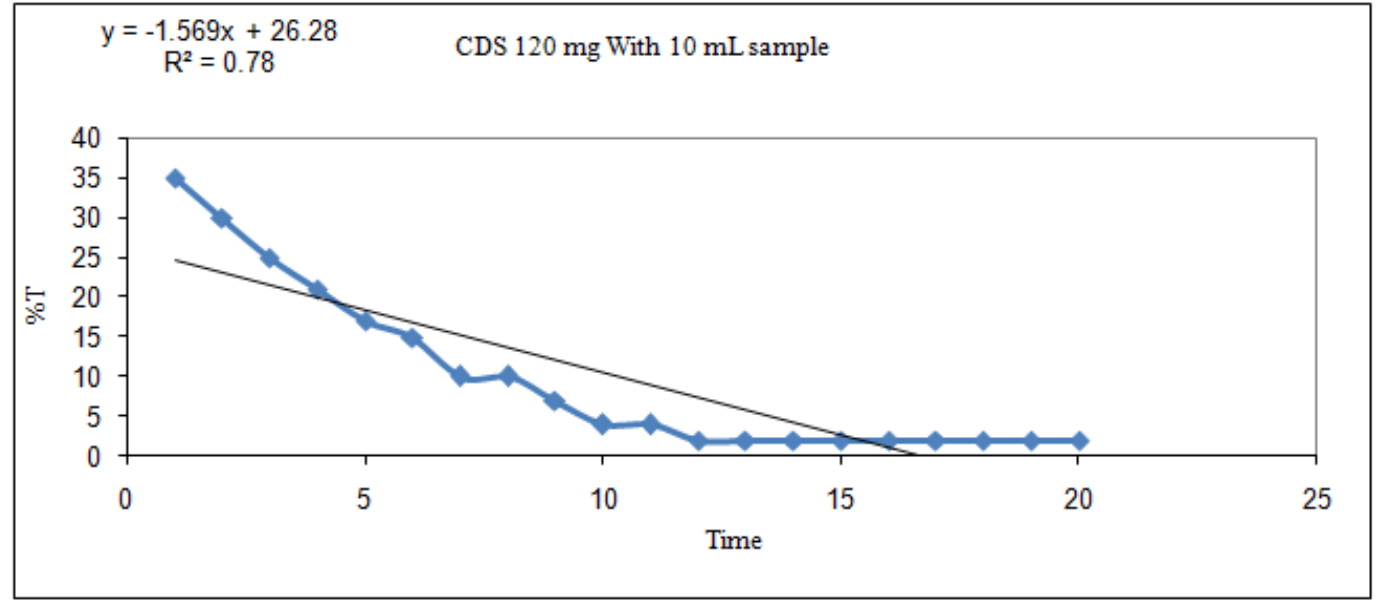

Fig-11

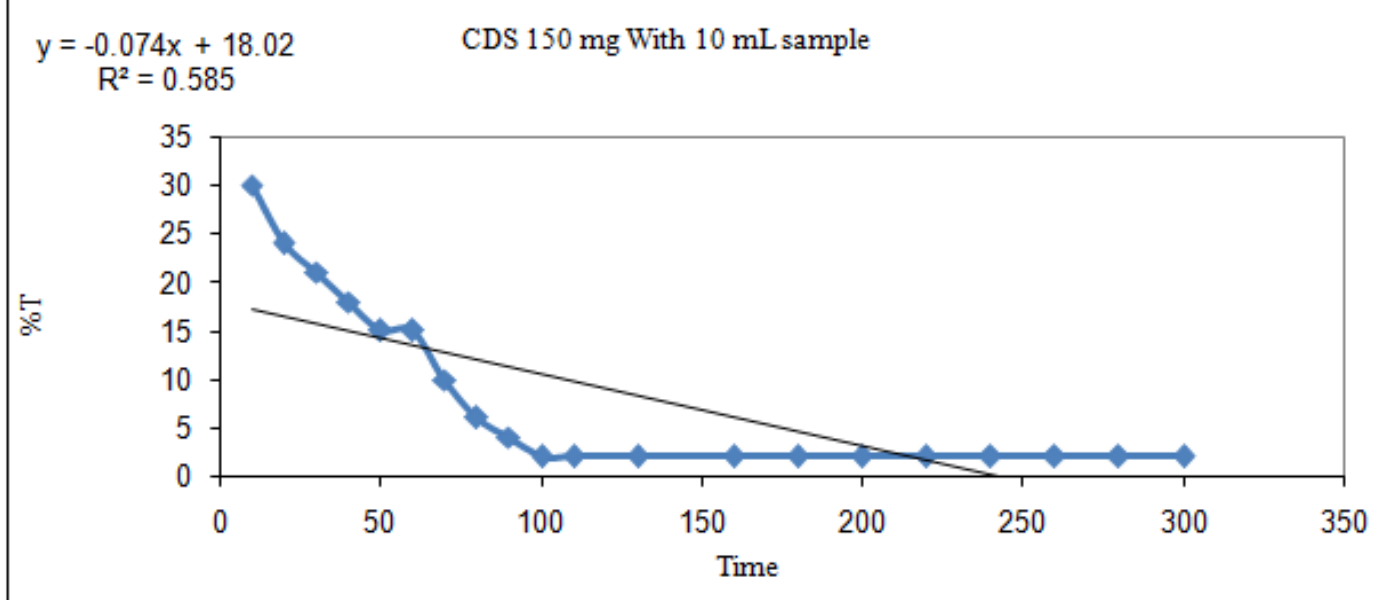

Fig-12

\section{Conclusion}

This paper describes the degradation of organic molecule through CDS nano catalyst/UV and this is pseudo first order kinetics, the kinetics of heterogeneous catalytic (CDS) reaction applied to waste water treatment. It's a novel experiment for the determination of the kinetics of photo catalytic degradation of organic molecule (COD) in aqueous solution. It further validates the importance of AOPs in degradation of waste water. In this method organic molecule are completely degraded through nano catalyst.

\section{References}

[1] Bumpus, J.A., Tricker, J., Andrzejewski, K., Rhoads, H., Tatarko, M., Remediation of water contaminated with azo dye: an

[2] undergraduate Laboratory experiment utilizing an inexpensive photocatalytic reactor, J. Chem. Educ., 76, 1680 (1998).

[3] Hoffmann, M.R, Martin, S.T., Choi, W., Bahnemann, D., Environmental applications of semiconductor photo catalysis, Chemical Reviews, 95, 69-96 (1996).

[4] N.Serpone, E. Pelizzetti, Photocatalysis: Fundamentals and Applications; John Wiley Sons, Inc.: New York, 603-634,1989.

[5] Matthews, R.W. Photooxidation of Organic Impurities in Water Using Thin Films of Titanium Dioxide. J. Phys. Chem., 91, 3328$3333,1987$.

[6] Taixing Wu, Tong Lin, Jincai Zhao,Hisao Hidaka,and Nic Serpon, CDS-assisted photodegradation of Dyes, Environ. Sci Technol, 33, 1379-1387 (1999).

[7] Al-Ekabi H, Serpone N, J. Phy. Chem. 92, 5726 (1988).

[8] R.J. Davis, J.L. Gainer, G. Neal, I-Wenwu. Photocatalytic decolonization of Wastewater Dyes. Wat. Environ. Res. 6 (1), 5053,1994 .

[9] $\wedge$ A b Clair N. Sawyer, Perry L. McCarty, Gene F. Parkin (2003). Chemistry for Environmental Engineering and Science (5 ${ }^{\text {th }}$ ed.) New York: McGraw-Hill. ISBN 0-07-248066-1

[10] Kaneko M, Okura, I, 2002.photocatalysis science and Technology. Springer,Japan

[11] Konstantinou, I.k,Albanis, T.A , 2004 CDS assisted degradation of azo dyes in aqueous solution . Kinetic and mechanism investigation .A review. Appl Catal B Environ.49,1-14

[12] CRAIG S. TURCHI AND DAVID F OLLIS "Photo catalytic Degradation of Organic Water Contaminants: Mechanisms involving Hydroxyl Radical Attack.” JOURNAL OF CATALYSIS 122, 178-192 (1990) 